\title{
PENGARUH BUDAYA ORGANISISASI TERHADAP PRODUKTITIVITAS KERJA KARYAWAN DENGAN MENGGUNAKAN METODE REGRESI LINEAR DI PT SURYA TOTO INDINESIA Tbk.
}

\author{
Junaedi \\ Program Studi Teknik Industri, Fakultas Teknik, Universitas Pamulang \\ dosen02341@unpam.ac.id
}

\begin{abstract}
ABSTRAK
Dilakukan penelitian tentang Pengaruh Budaya Organisisasi Terhadap Produktitivitas Kerja Karyawan Dengan Menggunakan Metode Regresi Linear Di Pt Surya Toto Indinesia Tbk. Dengan menghitung nilai regresi linearnya persamaan nya menjadi $\hat{Y}=20,529+0,664 \mathrm{X}_{1}$, disimpulkan budaya organisasai sangat berpengaruh terhadap produktifitas karywan dan sangat signifikan sebesar 46,1\%. Hasil pengujian hipotesis dengan $t$ hitung diperoleh $t_{\text {hitung }}>t_{\text {tabel }}$ atau $(11,319>1,976)$. Dengen diperkuat signifikansinya $0.000<0.05$ dengan $\mathrm{H}_{0}$ ditolak dan $\mathrm{H}_{1}$ artinya budaya Organisasi terhadap Produktifitas kerja berpengaruh positif dan signifikan secara parsial terhadap kinerja karyawan.
\end{abstract}

Kata Kunci: Budaya Organisasi, produktifitas, Regresi, hipotesis

\section{PENDAHULUAN}

Baik tidaknya seorang karyawan dapat dinilai melalui tingkat produktivitasnya. Menurut Sinungan (2003:12) "Produktivitas adalah kemampuan seperangkat sumber sumber ekonomi untuk menghasilkan sesuatu sebagai perbandingan antara pengorbanan (input) dengan menghasilkan (output) "

“ Produktivitas pada hakekatnya meliputi sikap yang senantiasa mempunyai pandangan bahwa metode kerja hari ini harus lebih baik dari hari kemaren dan hasil yang dapat diraih esok hari harus lebih banyak atau lebih bermutu dari pada hasil yang diraih hari ini (Komarudin, 1992: 121) " kemampuan memperoleh manfaat sebesar-besarnya dari sarana dan prasarana yang tersedia dengan menghasilkan output yang optimal, kalau mungkin yang maksimal (Sondang P, Siagian, $1982: 15)$.

Dari uraian diatas maka dapat dinyatakn bahwa Budaya Organisasi, Pelatihan dan keselamatan dan kesehatan kerja yang diterapkan oleh perusahan terhadap karyawannya akan menjadikan prilaku karyawan. Sehingga akan mempengaruhi produktivitas kerja karyawan. Dengan demikian semakin baik penerapan hal tersebut akan semakin baik produktivitas karyawannya.

\begin{abstract}
Berdasarkan hal-hal yang telah diuraikan di atas baik fenomena serta data empiris yang penulis sajikan, maka penulis sangat tertarik untuk mengakaji lebih lanjut permasalahan ini dalam bentuk penelitian dan mengambil judul, Pengaruh Budaya Organisasi Produktivitas Kerja Di Seksi Assembling Pt Surya Toto Indonesia Tbk Divisi Fitting .
\end{abstract}

\section{Kajian Teori}

\section{A. Pengertian Manajemen}

Manajemen merupakan usaha yang dilakukan secara bersama-sama untuk menentukan dan mencapai tujuan-tujuan organisasi dengan pelaksanaan fungsi-fungsi perencanaan (planning), pengorganisasian (organizing), pelaksanaan (actuating), dan pengawasan (controlling).

\section{B. Manajemen Sumber daya manusia}

Manajemen sumber daya manusia adalah pengelolalan sumberdaya manusia sebagai sumber daya atau aset utama melalui penerapan fungi manajemen maupun funfsi opersionalsehinmgga tujuan organisasi dapat di tetapkan dan dapat tercapai dengan baik. 


\section{Budaya Organisasi}

Budaya organisasi adalah suatu budaya yang dimiliki oleh orang-orang dengan karakter dan kulitas yang unik pada suatu organisasi. Pernyataan tersebut dapat didefinisikan sebagai filosofi bersama, ideology, nilai, asumsi, keyakinan, ekspektasi, perilaku, dan norma yang mengikat kebersamaan dalam suatu organisasi.

\section{Pelatihan}

Pada dasarnya, pelatihan adalah suatu aktivitas untuk meningkatkan kemampuan pegawai dengan mengalokasikan anggaran sebagai investasi. Hal yang searah di rumuskan bahwa pelatihan pada intinya adalah sebuah proses belajar. Oleh sebab itu, pelatihan didefinisikan sebagai satu proses mengajarkan keterampilan yang dibutuhkan pegawai baru untuk melakukan pekerjaannya (Gary Dessler, 2004). Sesungguhnya, pelatihan bukan hanya di khususkan untuk pegawai yang baru saja, melainkan juga pegawai lama yang akan di promosikan ke posisi tertentu.

\section{E. Keselamatan dan Kesehatan Kerja}

Keselamatan berasal dari kata selamat besumber dari bahasa inggris yaitu safety yang dihubungkan dengan keadaan bebasnya seseorang dari kondisi celaka (accident). Oleh sebab itu, keselamatan sebagai suatu pendekatan keilmuan maupun pendekatan praktis akan mempelajari beberapa faktor yang dapat menybabkan terjadinya kecelakan dan berupay mengembangkan beerbagai cara untuk meminimalisasi terjadinya kecalakaan. Menurut Silalahi dan Rumondang ( dalam Widodo 2015), keselamatn merupakan suatu usaha untuk mencegah suatu perbuatan dan kodisi tidak selamat yang dapat mengakibatkan kecelakaan, sedangkan kesehatan kerja yaitu terhindarnya dari penyakit yang mungkin akan timbul setelah memuali pekerjaannya.

F. Produktivitas Kerja Karyawan

Produktivitas adalah suatu pendekatan interdisipliner untuk menentukan tujuan yang efektif, pembuatan rencana, aplikasi penggunaan cara yang prosduktivitas untuk menggunakan sumber-sumber secara efisien, dan tetap menjaga adanya kualitas yang tinggi (Sinungan 2008:18).

\section{METODOLOGI PENELITIAN}

Tempat Penelitian di PT Surya Toto Indonesia Tbk, yang beralamat di Jalan MH Thamrin Km7 Tangerang Banten.

Penelitian dilakukan secara bertahap yang dimulai dari pra survey penelitian, pengajuan judul penelitian, mengajukan kajian pustaka yang sesuai dengan variabel yang dipilih dengan metode regresi linear.

\section{HASIL PENELITIAN DAN PEMBAHASAN}

A. Deskripsi Responden

\begin{tabular}{l}
\multicolumn{5}{c}{ Tabel 4.1 Jenis Kelamin Responden } \\
\begin{tabular}{|l|l|l|l|}
\hline \multirow{2}{*}{ No. } & \multirow{2}{*}{ Jenis Kelamin } & \multicolumn{2}{l|}{ Keterangan } \\
\cline { 3 - 4 } & & Jumlah & Presentase \\
\hline 1. & Laki-Laki & 141 & $92,76 \%$ \\
\hline 2. & Perempuan & 11 & $7,24 \%$ \\
\hline Total & & 152 & $100 \%$ \\
\hline
\end{tabular} Sumber : Data Primer yang diolah, 2017 \\
\hline
\end{tabular}

Berdasarkan dari tabel 4.1 dapat diketahui bahwa dari penelitian terhadap 152 orang responden menunjukkan bahwa responden dengan jenis kelamin laki-laki lebih banyak dari pada responden dengan jenis kelamin perempuan.

\begin{tabular}{l} 
Tabel 4.2 Usia Karyawan seksi Assembling \\
\begin{tabular}{|l|l|l|l|}
\hline \multirow{2}{*}{ No. } & \multirow{2}{*}{ Usia karyawan } & \multicolumn{2}{|l|}{ Keterangan } \\
\cline { 3 - 4 } & & Jumlah & Presentase \\
\hline 1. & $20-30$ & 115 & $75,66 \%$ \\
\hline 2. & $31-55$ & 37 & $24,34 \%$ \\
\hline Total & & 152 & $100 \%$ \\
\hline
\end{tabular} Sumber : Data Primer yang diolah, 2017 \\
\hline
\end{tabular}

Berdasarkan tabel 4.2. dapat dilihat bahwa responden yang berusia antara 20 - 30 tahun sebanyak 115 responden atau $75,66 \%$, sedangkan responden yang berusia antara 31 - 55 tahun sebanyak 37 responden atau $24,34 \%$ responden. 
Tabel 4.4 Jabatan karyawan

\begin{tabular}{|l|l|l|l|}
\hline \multirow{2}{*}{ No. } & \multirow{2}{*}{ Jabatan } & \multicolumn{2}{|l|}{ Keterangan } \\
\cline { 3 - 4 } & & Jumlah & Presentase \\
\hline 1 & Operator & 121 & $79,61 \%$ \\
\hline 2 & Senior Worker & 16 & $10,53 \%$ \\
\hline 3 & Grup Leader & 9 & $5,92 \%$ \\
\hline 4 & Foreman & 4 & $2,63 \%$ \\
\hline 5 & Supervisor & 2 & $1,32 \%$ \\
\hline Total & & 152 & $100 \%$ \\
\hline
\end{tabular}

Berdasarkan tabel 4.4 dapat dilihat bahwa responden yang dengan Jabatan Operator sebanyak 121 responden atau 76,61\%, jabatan Senior Worker sebanyak 16 responden atau $10,53 \%$, jabatan Grup Leader sebanyak 9 responden atau 5,92\%, jabatan Foreman sebanyak 4 responden atau $2,63 \%$ dan jabatan Supervisor sebanyak 2 responden atau $1,32 \%$ responden.

Tabel 4.5 Masa Kerja

\begin{tabular}{|l|l|l|l|}
\hline \multirow{2}{*}{ No. } & \multirow{2}{*}{ Masa Kerja } & \multicolumn{2}{|l|}{ Keterangan } \\
\cline { 3 - 4 } & & Jumlah & Presentase \\
\hline 1 & $0-10$ Tahun & 111 & $73,03 \%$ \\
\hline 2 & $11-20$ Tahun & 11 & $7,24 \%$ \\
\hline 3 & $21-30$ Tahun & 27 & $17,76 \%$ \\
\hline 4 & $31-41$ Tahun & 3 & $1,97 \%$ \\
\hline Total & & 152 & $100 \%$ \\
\hline
\end{tabular}

Berdasarkan tabel 4.5 dapat dilihat bahwa responden yang dengan masa Kerja 0 - 10 tahun 111 responden atau $73,03 \%$, yang memiliki masa kerja 10 - 20 tahun sebanyak 11 responden atau $7,24 \%$, masa kerja 21 - 30 tahun sebanyak 27 responden atau $17,76 \%$, sedangkan yang memiliki masa kerja 31 - 41 tahun sebanyak 3 responden atau $1,97 \%$ responden.

\section{B. Hasil Rekapitulasi Kuesioner}

Hasil Kuisoner menyimpulkan bahwa keselamatan dan kesehatan kerja pada seksi Assembling di PT Surya Toto Indonesia Tbk, divisi Fitting mendapat respon dengan baik dengan jumlah kuesioner yang disebar sebanyak 152 kuesioner, yang kembali sebanyak 152 koesioner atau seberar 100\%. Dari 152 responden yang mengembalikan hasil kuesioner yang menjawab

a. Tidak setuju (TS) sebesar 13/2280 x $100 \%=0,57 \%$,

b. Kurang setuju (KS) sebesar $31 / 2280 \mathrm{x}$ $100 \%=1,36 \%$,

c. Netral (N) sebesar $153 / 2280 \times 100 \%=$ $6,71 \%$,

d. Setuju (S) sebesar 1253/2280 x 100\%= $54,96 \%$

e. Sangat setuju (SS) sebesar $830 / 2280 \mathrm{x}$ $100 \%=36,40 \%$.

C. Hasil Uji Instrumen Penelitian

Tabel 4.10

Hasil Uji Validitas Varibel Budaya organisasi $\left(\mathrm{X}_{1}\right)$

\begin{tabular}{|c|l|c|c|c|}
\hline No & \multicolumn{1}{|c|}{ Pernyataan } & $\mathbf{r}$ Hitung & $\mathbf{r}$ Tabel & Keterangan \\
\hline 1 & Butir permyataan 1 & 0,621 & 0,1598 & Valid \\
\hline 2 & Butir pemyataan 2 & 0,602 & 0,1598 & Valid \\
\hline 3 & Butir pemyataan 3 & 0,726 & 0,1598 & Valid \\
\hline 4 & Butir pemyataan 4 & 0,636 & 0,1598 & Valid \\
\hline 5 & Butir pemyataan 5 & 0,622 & 0,1598 & Valid \\
\hline 6 & Butir permyataan 6 & 0,551 & 0,1598 & Valid \\
\hline 7 & Butir pemyataan 7 & 0,587 & 0,1598 & Valid \\
\hline 8 & Butir pemyataan 8 & 0,691 & 0,1598 & Valid \\
\hline 9 & Butir pemyataan 9 & 0,643 & 0,1598 & Valid \\
\hline 10 & Butir permyataan 10 & 0,685 & 0,1598 & Valid \\
\hline 11 & Butir pemyataan 11 & 0,618 & 0,1598 & Valid \\
\hline 12 & Butir pemyataan 12 & 0,708 & 0,1598 & Valid \\
\hline 13 & Butir pemyataan 13 & 0,492 & 0,1598 & Valid \\
\hline 14 & Butir pemyataan 14 & 0,585 & 0,1598 & Valid \\
\hline 15 & Butir pemyataan 15 & 0,646 & 0,1598 & Valid \\
\hline
\end{tabular}

Dari tabel diatas dapat kita simpulkan semua pernyataan memiliki $r$ hitung > r-tabel, sehingga dapat dinyatakan semua pernyataan valid, dengan demikian semua pernyataan atau pertanyaan dapat dilanjutkan

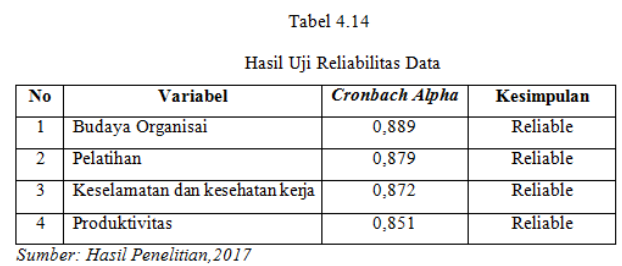

Berdasarkan hasil uji reliabilitas pada tabel 4.17, dapat diketahui bahwa seluruh variabel yang digunakan reliable, karena memiliki nilai Cronbach Alpha lebih besar dari 0,6. 
Normal P.P Plot of Regression Standardized Residual

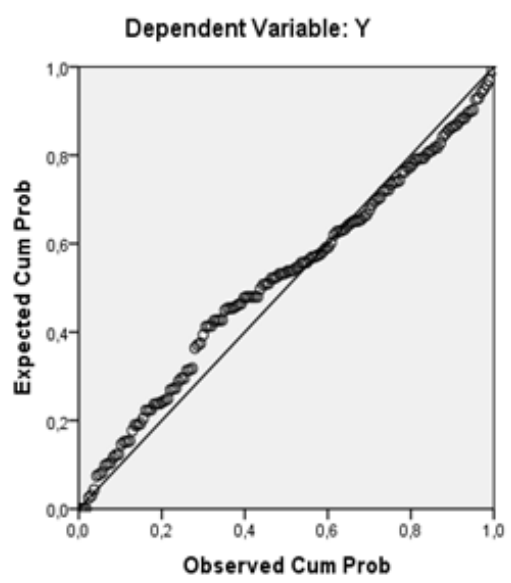

Dari grafik di atas dapat dilihat bahwa titik-titik menyeba garis atau mengikuti garis sehingga dapat diambil disekitar diagonal, kesimpulan bahwa nilai residual yang dihasilkan regresi tersebut normal.

Scatterplot

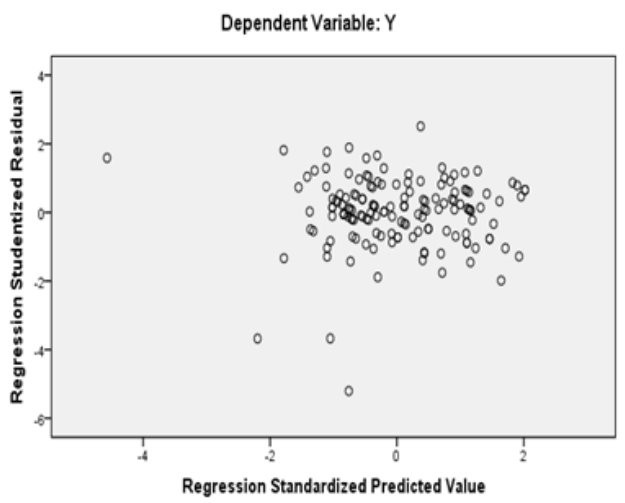

Dari output gambar di atas dapat kita lihat bahwa titik-titik tidak membentuk pola yang jelas, dan titiktitik menyebar di atas dan di bawah angka 0 pada sumbu Y. Jadi dapat diambil kesimpulan bahwa data penelitian tidak terjadi masalah heteroskedastisitas dalam model regresi.

\section{Analisa Data}

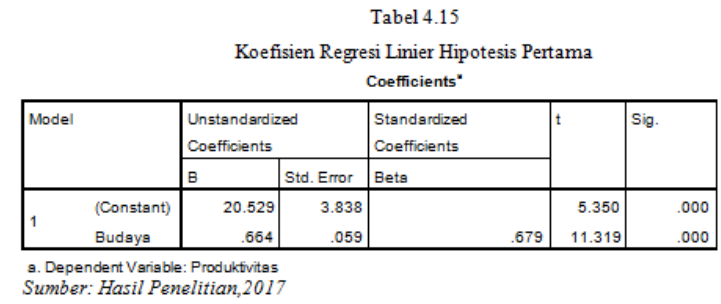

Berdasarkan tabel diatas, maka persamaan regresi linier dalam penelitian ini adalah:

$\hat{\mathrm{Y}}=20,529+0,664 \mathrm{X}_{1}$

Pada persamaan tersebut dapat diketahui konstanta sebesar 20,529 menyatakan bahwa jika tidak ada kenaikan nilai dari variabel Budaya organisasi $\left(\mathrm{X}_{1}\right)$, maka nilai Produktivitas kerja (Y) adalah 20,529. Koefisien regresi sebesar 0,664 menyatakan bahwa setiap penambahan satu atau nilai Budaya Organisasi akan memberikan peningkatan niali Produktivitas sebesar 0,664.

Uji $\quad t$ untuk menguji signifikansi konstanta dan variabel dependen (Produktivitas) kerja. Kriteria uji koefisien regresi dari variabel Budaya organisasi terhadap Produktivitas sebagai berikut :

Hipotesis dalam bentuk kalimat :

$\mathrm{H}_{1}$ : Budaya Organisasi berpengaruh secara signifikan terhadap Produktivitas.

$\mathrm{H}_{0} \quad$ : Budaya organisasi tidak berpengaruh secara signifikan terhadap Produktivitas

Hipotesis dalam bentuk statistic :

$\mathrm{H}_{1}: \mathrm{r}_{\mathrm{X} 1 \mathrm{Y}} \neq 0$

$\mathrm{H}_{\mathrm{o}}: \mathrm{r}_{\mathrm{X} 1 \mathrm{Y}}=0$

Dasar pengambilan keputusan dengan membandingkan nilai $t$ hitung dengan nilai $t_{\text {tabel, }}$, sebagai berikut :

Jika nilai $t_{\text {hitung }}>$ nilai $t_{\text {tabel }}$, maka $\mathrm{H}_{0}$ ditolak artinya koefisien regresi signifikan.

Jika nilai $t_{\text {hitung }}<$ nilai $t_{\text {tabel }}$, maka $\mathrm{H}_{0}$ diterima artinya koefisien regresi tidak signifikan.

Berdasarkan tabel di atas besarnya nila i $t_{\text {hitung }}$ untuk variabel Budaya organisasi $\left(\mathrm{X}_{1}\right)$ $=11,319$

Nilai $t_{\text {tabel }}$ dengan tingkat signifikansi $(\alpha)=0,05$ dan $\mathrm{dk}($ derajat kebebasan $)=152$ (jumlah data - 2 ), didapat nilai 1,976.

Keputusan:

Karena nilai $t_{\text {hitung }}>t_{\text {tabel }}$ atau $11,319>$ 1,976, maka $\mathrm{H}_{\mathrm{o}}$ ditolak dan $\mathrm{H}_{1}$ diterima

Terlihat juga pada kolom Sig(signifikansi) pada tabel di atas terdapat nilai 0,000 atau probabilitas jauh dibawah 0,05 . Berdasarkan hasil yang diperoleh maka menolak $\mathrm{H}_{0}$ dan menerima $\mathrm{H}_{1}$ untuk variabel Budaya Organisasi, artinya secara parsial variabel Budaya Organisasi berpengaruh positif dan signifikan terhadap Produktivitas 
kerja karyawan Assembling PT Surya Toto Indonesia Tbk, Divisi Fitting.

Uji t untuk menguji signifikansi kons tanta dan variabel dependen (Produktivitas) kerja. Kriteria uji koefisien regresi dari variabel Pelatihan terhadap Produktivitas sebagai berikut :

Hipotesis dalam bentuk kalimat :

$\mathrm{H}_{1}$ : Pelatihan berpengaruh secara signifikan terhadap Produktivitas.

$\mathrm{H}_{0}$ : Pelatihan tidak berpengaruh secara signifikan terhadap Produktivitas

Hipotesis dalam bentuk statistic :

$\mathrm{H}_{1}: \mathrm{r}_{\mathrm{X} 2 \mathrm{Y}} \neq 0$

$\mathrm{H}_{\mathrm{o}}: \mathrm{r}_{\mathrm{X} 2 \mathrm{Y}}=0$

Dasar pengambilan keputusan dengan memba ndingkan nilai $t_{\text {hitung }}$ dengan nilai $t_{\text {tabel }}$, sebagai berikut :

Jika nilai $\mathrm{t}_{\text {hitung }}>$ nilai $\mathrm{t}_{\text {tabel, }}$, maka $\mathrm{H}_{0}$ ditolak artinya koefisien regresi signifikan.

Jika nilai $t_{\text {hitung }}<$ nilai $t_{\text {tabel }}$, maka $\mathrm{H}_{0}$ diterima artinya koefisien regresi tidak signifikan.

D. Pembahasan

Pengaruh Budaya Organisasi $\left(\mathrm{X}_{1}\right)$ terhadap Produktivitas (Y)

Hasil pengujian pengaruh Budaya Organisasi terhadap Produktivitas kerja secara statistik menunjukkan hasil yang signifikan. Hal ini di tunjukkan oleh persamaan regresi linier dalam penelitian ini adalah: $\hat{Y}=20,529+0,664 X_{1}$, nilai koefisien regresi sebesar 0,664 menyatakan bahwa vairabel Budaya Organisai berpengaruh positif dan signifikan terhadap produktivitas kerja di seksi Assembling PT surya toto Indonesia Tbk, Divisi Fitting.

Nilai $t_{\text {hitung }}$ untuk variabel Budaya organisasi $\left(\mathrm{X}_{1}\right)=11,319$. Nilai $t_{\text {tabel }}$ dengan tingkat signifikansi $(\alpha)=0,05$ dan $\mathrm{dk}($ derajat kebebasan $)=152$ (jumlah data -2 ), didapat nilai 1,976 .

Keputusan:

Karena nilai $\mathrm{t}_{\text {hitung }}>\mathrm{t}_{\text {tabel }}$ atau $11,319>1,976$, maka $\mathrm{H}_{\mathrm{o}}$ ditolak. $\mathrm{H}_{1}$ diterima

\section{KESIMPULAN DAN SARAN}

Budaya Organisasi berpengaruh positif dan signifikan terhadap Produktivitas kerja sebesar 46,1\%. Hal ini menunjukkan bahwa
Budaya Organisasi yang tinggi akan meningkatkan Produktivitas Kerja karyawan. Dari pengujian hipotesis diperoleh $t_{\text {hitung }}>t_{\text {tabel }}$ atau $(11,319>1,976)$ hal ini diperkuat dengan signifikansi $0,000<0,05$, dengan demikian $\mathrm{H}_{0}$ ditolak dan $\mathrm{H}_{1}$ diterima artinya terdapat pengaruh yang positif dan signifikan secara parsial antara Budaya Organisasi terhadap Produktivitas kerja karyawan.

DAFTAR PUSTAKA

Wijayanti, 2008. Manajemen. Mitra Cendikia Press, Yogyakarta.

Sinungan, Muchdarsyah, 2007. Produktivitas Apa dan Bagaimana, Penerbit Bumi Aksara, Jakarta.

Hasibuan, M. S. P (2007:2) dalam bukunya Manajemen dasar

Eko Widodo ,Suparno. 2015.” Manajemen Pengembangan Sumber Daya Manusia”.Yogyakarta: Pustaka Pelajar

Kusriyanto, Bambang. 2000. "Meningkatkan Efektifitas Karyawan". Pustaka Binama Pressindo, Jakarta.

Hasibuan, Malayu, S.P. 2003. Manajemen Dasar, Pengertian dan Masalah. Jakarta : PT Toko Gunung Agung.

Muchdarsyah Sinungan, 2008, Produktivitas Apa dan Bagaimana, edisi 2, Jakarta:

Sedarmayanti. (2001). Sumber Daya Manusia Dan Produktivitas Kerja. Bandung: CV. Mondar Maju.mi Aksara.

Hasan, M. Iqbal, Pokok-pokok Materi Metodologi Penelitian dan Aplikasinya, Ghalia Indonesia, Bogor, 2002.

Ghozali, Imam. 2009. "Aplikasi Analisis Multivariate dengan Program SPSS “. Semarang : UNDIP. 
Sugiyono. 2011. Metode Penelitian Kuantitatif, Kualitatif dan R\&D. Bandung: Afabeta

Sugiyono. 2010. Metode Penelitian Pendidikan Pendekatan Kuantitatif, kualitatif, dan R\&D. Bandung: Alfabeta

Ghozali, Imam, 2001, Aplikasi Analisis Multivariate Dengan Program SPSS, Badan Peneliti Universitas Diponegoro, Semarang.

Sugiyono. 2012. Metode Penelitian Kuantitatif Kualitatif dan R\&D. Bandung: Alfabeta.

Drs. H. Malayu Hasibuan, 2007. Manajenen Sumber Daya Manusia. Jakarta : Cetakan 9. PT. Bumi Aksara.

Anwar Prabu Mangkunegara, 2001. Manajenen Sumber Daya Perusahaan, PT Remaja Rosdayakarya, Bandung.

Mangkunegara, Anwar prabu. 2001, Manajemen Sumber Daya Manusia Perusahaan, Bandung

Fuanida, A. (2012). Pengaruh Pelatihan, Disiplin Kerja, dan Motivasi Terhadap Produktivitas Kerja Karyawan CV. Sapu Dunia Semarang. Jurnal Ilmu Administrasi Bisnis, 1(2), 93-105.

Prajitiasari, E. D. (2012). Pengaruh Pendidikan dan Pelatihan pada Karyawan Terhadap Produktivitas Kerja pada PT. Bank Rakyat Indonesia (Persero) Cabang Tulungangung. Jurnal Media Mahardhika Fakultas Ekonomi Universitas Jember.

Henry Simamora. 2001. Manajemen Sumber Daya Manusia. STIE YKPN. Yogyakarta.
A. Sihotang. Manajemen Sumber Daya Manusia. Jakarta : Pradnya Paramita

Henry Simamora. 2001. Manajemen Sumber Daya Manusia. STIE YKPN. Yogyakarta.

Sutrisno, Edy. 2011. Manajemen Sumber Daya Manusia. Cetakan Ketiga Kencana Prenada Media Group, Jakarta

Asri Laksmi. 2011. Budaya Organisasi. Graha Ilmu. Yogyakarta.

Wirawan. 2007. Budaya dan Iklim Organisasi. Jakarta : Salemba Empat 